OPEN ACCESS

Edited by:

Changqiang Wu,

North Sichuan Medical College, China

Reviewed by:

Roshankumar Patil,

HealthCare Global Enterprises Lto

(HCG), India

Gaurav Sharma,

University of Texas Southwestern

Medical Center, United States

*Correspondence:

Kaixuan Yang

kaixuanyangmd@hotmail.com

${ }^{\dagger}$ These authors have contributed equally to this work and share first authorship

Specialty section: This article was submitted to

Cancer Imaging and Image-directed Interventions,

a section of the journal

Frontiers in Oncology

Received: 22 December 2020

Accepted: 30 July 2021

Published: 27 August 2021

Citation:

Li M, Zhang Q and Yang K (2021) Role of MRI-Based Functional Imaging in Improving the Therapeutic Index of Radiotherapy in Cancer Treatment.

Front. Oncol. 11:645177.

doi: 10.3389/fonc.2021.645177

\section{Role of MRI-Based Functional Imaging in Improving the Therapeutic Index of Radiotherapy in Cancer Treatment}

\author{
Mei $\mathrm{Li}^{1,2+}$, Qin Zhang ${ }^{2+}$ and Kaixuan Yang ${ }^{1 *}$ \\ 1 Department of Gynecology and Obstetrics, Key Laboratory of Birth Defects and Related Diseases of Women and Children, \\ Ministry of Education, West China Second University Hospital, Sichuan University, Chengdu, China, ${ }^{2}$ West China School of \\ Medicine, West China Hospital, Sichuan University, Chengdu, China
}

Advances in radiation technology, such as intensity-modulated radiation therapy (IMRT), have largely enabled a biological dose escalation of the target volume (TV) and reduce the dose to adjacent tissues or organs at risk (OARs). However, the risk of radiation-induced injury increases as more radiation dose utilized during radiation therapy (RT), which predominantly limits further increases in TV dose distribution and reduces the local control rate. Thus, the accurate target delineation is crucial. Recently, technological improvements for precise target delineation have obtained more attention in the field of RT. The addition of functional imaging to RT can provide a more accurate anatomy of the tumor and normal tissues (such as location and size), along with biological information that aids to optimize the therapeutic index (TI) of RT. In this review, we discuss the application of some common MRI-based functional imaging techniques in clinical practice. In addition, we summarize the main challenges and prospects of these imaging technologies, expecting more inspiring developments and more productive research paths in the near future.

\section{Keywords: functional imaging, organs at risk, target volume, radiation therapy, therapeutic index}

\section{INTRODUCTION}

Radiation therapy (RT) is the cornerstone of curative cancer care (1). Ideally, the optimal RT strategy is supposed to deliver the highest potential radiation dose to the tumor target volume (TV) without affecting nearby structures or organs at risk (OARs). To meet the requirement, radiation oncology has undergone a huge transition in the last decades from 2D therapy to 3D conformal RT (3DCRT) and intensity-modulated RT (IMRT), and even to intensity-modulated proton therapy (IMPT), which allows for better performance in terms of dose escalation in the TV and dose reduction in the OARs. Theoretically, therapeutic index (TI) is optimized by maximizing the dose in the TV while minimizing the dose in the OARs in the treatment plan (Figure 1D).

With regard to IMPT, it has been widely studied due to its unique depth-dose characteristics of protons, which can increase the dose to the TV while reducing the dose exposure to normal tissue, 


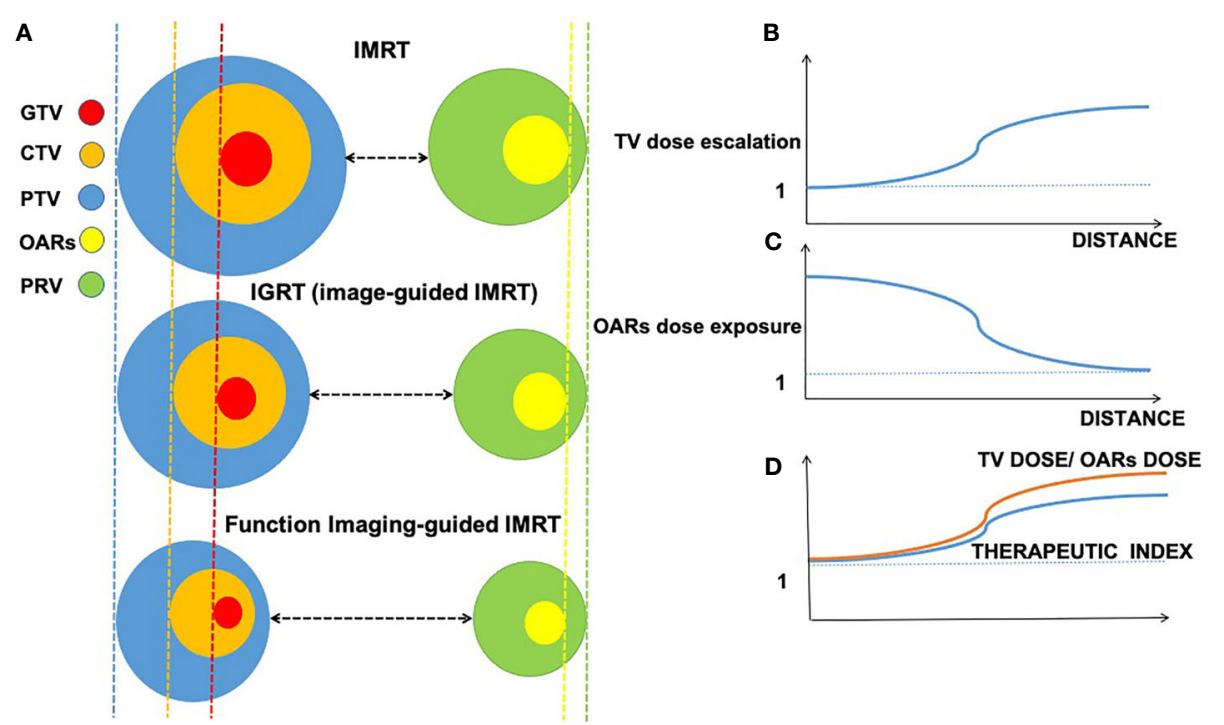

FIGURE 1 | Interaction among imaging-guided techniques, treatment margins of tumor target, and organs at risk (OARs) based on the accuracy of imaging approaches. Decreasing volume around gross tumor volume (GTV, in red), clinical target volume (CTV, in orange), planning target volume (PTV, in blue), planning organ at risk volume (PRV, in green), and organs at risk (OARs, in yellow); distance changes between treatment margins and OARs in intensity-modulated radiation therapy (IMRT), image-guided radiation therapy (IGRT), and function imaging-guided IMRT. (A) Relations between distance ( $\mathrm{x}$-axis) of gross target and organ at risk. (B) Relations between the distance (x-axis) and TV dose escalation (y-axis). (C) Relations between the distance (x-axis) and OARs dose exposure (y-axis).

(D) Relations between TV dose/OARs dose and therapeutic index.

however, the majority of studies on the application of IMPT is based on small-scale studies and is poorly cost-effective (2). Therefore, herein, we focus on photon-based RT techniques such as 3DCRT and IMRT, which are currently the main RT strategies in large-scale clinical practice, despite the lack of TI optimization during RT. Fortunately, a growing body of evidence suggests that the integration of functional imaging techniques into RT brings hope for improving TI based on photon-based RT. In RT, imaging plays a critical role in tumor location, staging, target delineation, and outcome monitoring (3). In contrast to conventional IMRT and imaging-guided RT (IGRT), functional imaging-guided IMRT tends to provide a more accurate delineation of TV and OARs, resulting in diminishing treatment margin of the gross tumor volume (GTV), clinical target volume (CTV), and planning target volume (PTV) in tumor target and a smaller volume of OARs and planning OAR volume (PRV) in OARs (Figure 1A). In addition to anatomical information (such as location and size), functional imaging provides the physiological and functional status of the tumor and its surroundings compared with conventional magnetic resonance imaging (MRI) (3). Currently, functional imaging plays various roles in radiation oncology, such as tumor localization, staging, target delineation, assessment of early response to therapy, prognosis, and monitoring recurrence (4).

In general, functional imaging has widely enabled clinicians to improve TI ratios by reducing the risk of geographic miss and selectively increasing radiotherapy (RT) dose to the TV, and minimizing unnecessary dose exposure to the OARs simultaneously. In this review, we outline several common
MRI-based functional imaging techniques that used in the field of RT to explore improvement in TI ratios. Furthermore, we summarize current challenges and prospects.

\section{FUNCTIONAL IMAGING}

At present, many functional imaging techniques have been gradually integrated into oncologic RT planning. Herein, we review some common imaging techniques in clinical practice, including diffusion-weighted (DW) imaging (DWI), intravoxel incoherent motion DWI (IVIM-DWI), MR-spectroscopic imaging (MRSI), dynamic susceptibility contrast (DSC), dynamic contrast-enhanced (DCE), diffusion tensor imaging (DTI)-MRI, and blood oxygenation level-dependent functional MRI (BOLD-fMRI) (Table 1).

\section{Diffusion-Weighted MRI}

DWI is a simple and readily available functional imaging technique with capability to visualize the motion of the water molecules (also called Brownian motion) in biological tissues (5). DWI can evaluate the differences in tissue cellular density and offer visibility of cellular construction $(102,103)$. Sensitized bvalue, known as, the real diffusion weighting (measured in s/ $\mathrm{mm}^{2}$ ), is used to measure the levels of diffusion weighting applied. Motion-sensitizing gradients are used for parameter acquisition. Thus, there is no need for contrast injection on DW-MRI due to its tissue contrast. The amount of diffusion (of water molecules) in different tissues can be quantificationally evaluated using the apparent diffusion 
coefficient (ADC) value (6) and then presented as a map, which holds better diffusion than traditional DWI. ADC value can be calculated by changing gradient amplitude using different bvalues (104-106) and at least two b-values (107). In clinical practice, to achieve the lower mobility of water molecules and shorter diffusion distances in these tissues, using a larger b-value (e.g., $\mathrm{b}=500 \mathrm{~s} / \mathrm{mm}^{2}$ ) on DWI is suggested.

Generally, the spread of water molecules on DW-MRI is restricted on malignant lesions with hypercellular areas or complex structures, presenting a high signal on DWI and accompanying low ADC value $(108,109)$. Clinical practice shows (110) that the standard ADC value obtained by the traditional single-index DWI model is affected by the water molecule diffusion and microcirculation perfusion in the tissue and cannot well reflect the movement of water molecules in the tumor tissue. IVIM-DWI introduced by Le Bihan $(5,27)$ can more accurately assess diffusion movement and microcirculation perfusion in tumor tissues due to its ability to separate diffusion and perfusion. IVIM-based parameters involve pure diffusion coefficient (D), pseudodiffusion coefficient $\left(D^{*}\right)$, and perfusion fraction ( $f$ ).

Based on the fact that the ADC value and signal intensity between tumor and normal tissue are significantly different, recently, DWI has been gradually explored to accurately delineate TV and OARs in radiation treatment planning. For example, it has been indicated that the addition of DWI to MRI can better distinguish lung cancer from atelectasis (7). DWI also takes advantage of nodal staging (8-10); thus, DWI provides smaller nodal TV delineation than conventional imaging (8). Similarly, DWI provides smaller rectal tumor volume (GTV) delineation than does T2-weighted (T2W) MRI (11-13), and probably because DWI provides a better edge contrast than T2W images (111). These findings indicate that a better RT boost to TV is possible. The quantitative data provided by DW-MRI could reflect intratumoral heterogeneity, highlighting more radioresistant areas $(14,15)$. Subsequently, elective dose escalation can be individually delivered to these areas. Moreover, DWI may be a potential tool to evaluate the salivary gland function in head and neck cancer (HNC) patients (16), resulting in the accurate protection for normal tissue, also with the ability to predict RT-induced xerostomia incident in RT. Several studies conclude that ADC histogram has a promising value of predicting overall survival (OS) and progression-free survival (PFS) and risk stratification in recurrent glioblastoma patients treated with bevacizumab (19-22).

Regarding clinical applications, IVIM-DWI can be used to detect positive resection margins in breast cancers $(30,31)$, lung tumors (26), and hepatic lesions in liver cancer $(32,33)$; and the diagnostic efficacy of $\mathrm{D}$ values is the highest $(28,29)$. A metaanalysis showed that the IVIM-DWI parameter ( $D$ value) showed better diagnostic performance than mono-exponential ADC (26). In addition, IVIM plays a pivotal role in benign and malignant identification $(33,34)$, especially for the $\mathrm{D}$ value (33). The $\mathrm{D}$ value is superior to $\mathrm{ADC}$ in distinguishing benign and malignant lesions (35). Moreover, IVIM-DWI-derived parameters can be used to grade malignant lesions $(28,34,36)$ and have the potential to differentiate true progression from pseudoprogression after early chemoradiotherapy in glioblastoma multiforme $(\mathrm{GBM})(23,24)$. Besides, IVIM can predict treatment response, such as parotid changes and vertebral bone marrow changes $(17,18)$. Taken together, the ability of IVIM-DWI to detect and identify benign and malignant would be helpful in target delineation and OAR avoidance in RT. Regarding tumor grading, IVIM-DWI may aid in predicting tumor aggressiveness and prognosis. In terms of pseudo/true progression identification and prediction of treatment response, IVIM may help to determine early therapeutic intervention and improve prognosis.

Overall, DWI may be a promising tool to obtain a better TI when being incorporated into RT planning assistance. However, some limitations of DWI, such as geometric distortions, which are closely related to TV delineation, and uncertainty of diffusion parameters, where low reproducibility means high variations, impede its widespread use within clinical practice. To solve this issue, conjunction with other MR images is suggested such as higher-resolution anatomic images, high-quality data with different b-values, and, if possible, contrast material-enhanced images (25).

\section{MR-Spectroscopic Imaging}

MRSI allows non-invasive measurement of biochemical information in tissues, especially in the brain with the existence of tumors. MRSI is also an analytical and noninjected contrast agent (CA) technique without ionizing radiation, related to MRI in vivo $(37,38)$. However, unlike MRI, which can only identify the anatomic structure and location of a tumor or normal tissue, MRSI can be used to determine the concentration and presence of various biochemical substances, often referred to as "metabolites" because of their role in metabolism. Therefore, MRSI can effectively supplement the characterization of tissue beyond MRI function. In recent years, proton MRSI has gained a great popularity due to its higher sensitivity and greater convenience, since proton MRSI does not need hardware modification while being performed on most MRI machines. Therefore, the remainder of this article in brain tumor studies focuses on protocols for ${ }^{1} \mathrm{H}$-MRSI. The common metabolites of ${ }^{1} \mathrm{H}$-MRSI include choline (Cho), $\mathrm{N}$-acetyl aspartate (NAA), lactate (Lac), and creatine $(\mathrm{Cr})$ in clinical routine (37).

In normal conditions, NAA exists in the intact neuronal and axonal structures, and its reduction demonstrates loss or damage of neuronal tissue (40). Cho is associated with phospholipid membrane turnover, and an increase in Cho indicates a process of leading to elevated glial proliferation and membrane synthesis (41). Lactate is implicated in various cancer mechanisms such as facilitating cancer cell proliferation and angiogenesis (112). Creatine is related to cellular energy metabolism. It is considered a useful reference metabolite due to its relative stability in different pathological processes involved in the central nervous system. In malignant tumors, NAA is reduced or lost since neurons are replaced by neoplastic tissue; Cho is increased directly; lactate may implicate a high level of 
malignancy (41). Based on the above, the NAA/Cho ratio is a sensitive marker for brain tumors, with the potential to distinguish active tumors from normal tissue and other noncancerous lesions, such as necrosis (42). Cho/NAA ratio is widely utilized to describe tumor volume and invasion, because these metabolites change inversely in the tumor, increasing contrast (47). At present, the application of MRSI in clinical practice is involved in differential diagnosis (43-46), classification $(45,46)$, staging (46), treatment planning $(49,50)$, and posttreatment monitoring (54). Moreover, Lac/Cr, NAA/Cho, and Lac/NAA can predict overall survival (OS) and progression free survival (PFS) (41).

Herein, we mainly focus on the use of MRSI in radiation planning. In glioma, compared with conventional RT alone, adding of MRSI could provide metabolism information of tumor cells and OARs, resulting in more accurate target delineation (50). Croteau et al. conducted a study in 31 lowand high-grade-glioma patients. Their findings showed that MRSI can more accurately define the tumor boundary and normal tissues and can quantify the extent of the disease compared with conventional MRI via histopathological validation (54). Pirzkall et al. studied 34 patients with highgrade gliomas (52). When using T2 to define high-risk regions, the volume is extended by as much as $28 \mathrm{~mm}$ as compared with tumor definition from MRSI. Thus, the MRSI technique may have the potential to accurately optimize dose distribution of tumor TV and reduce the exposure to normal tissue (52). Moreover, Narayana et al. showed that $\mathrm{Cho} / \mathrm{Cr}$ greater or equal to 3 defined by MRSI reduced $40 \%$ GTV volumes (GTVs) compared with GTVs defined by T1-weighted MRI (49). A study by Deviers et al. showed that tumor areas with lactate-to- $N$-acetyl aspartate ratio (LNR) 0.4 voxels before RT are likely to relapse, suggesting additional biological TVs for dose painting in GBM (53). In addition, a small study demonstrates that MRSI can aid in the delineation of hypoxic regions in solid tumors by exploring the metabolic outcome of tumor hypoxia, presenting increased total choline-containing metabolites (tCho) and lipid $\mathrm{CH} 3$ in breast tumors (51). Previous studies demonstrated that MRSI possesses great potential for the differentiation of tumor recurrence from radiation necrosis (37, $55,56)$. This technology would be helpful for reirradiation settings in brain tumors due to its accurate delineation of recurrent lesions and successful avoidance of normal structures or radiation-induced reactions.

Overall, it seems that MRSI has been gradually and widely used to improve treatment planning for RT, with the ability to deliver dose escalation at particular tumor targets and reduce dose exposure to OARs. Even for recurrent disease, MRSI may perform well in improving TI, such as identifying and predicting tumor lesion recurrence. However, we should also be aware of the limitations of MRSI, such as the presence of spectral artifacts, which can result in false information, and lower specificity, although spectral artifacts may be solved by the automatic testing system (57) and by obtaining a higher field strength, like using 3T (113). A combination between MRSI and DW-MRI may improve the specificity of MRSI (114). However, other obstacles in MRSI, concerning low spatial resolution, long-time

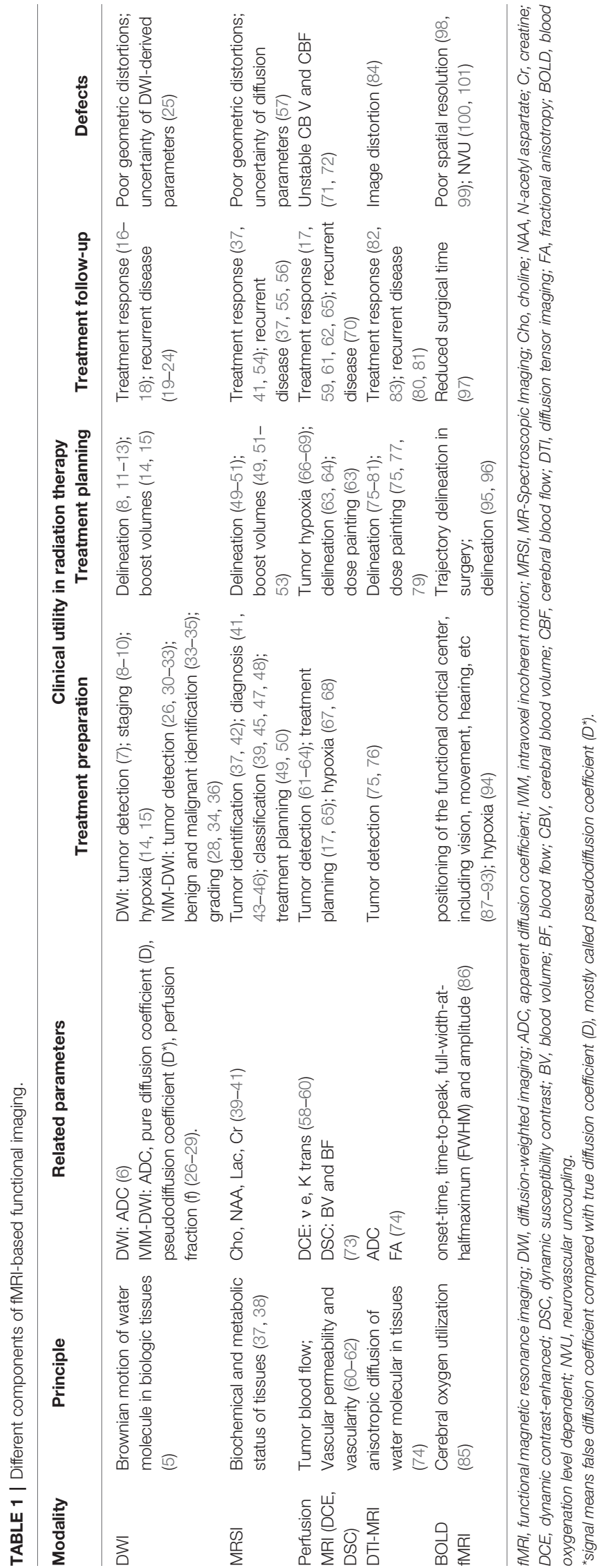


acquisition, and unstable acquisition of high-quality spectral images, have impeded the widespread translation of MRSI in clinical practice.

\section{Perfusion MRI}

Perfusion MRI is a well-established perfusion imaging technique, mainly including three techniques: DSC, DCE, and arterial spin labeling (ASL) MRI. Based on perfusion MRI modality, different parameters could be calculated, such as blood volume (BV) and blood flow $(\mathrm{BF})$ in DSC, also the transfer rate constant $\left(\mathrm{K}^{\text {trans }}\right)$ and the extravascular extracellular volume fraction (Ve) value in DCE. In perfusion MRI, individuals under inspection need a gadolinium-based agent via a peripheral vein during the continuous imaging process.

DSC refers to the BF through a certain tissue in a unit of time, which is an important physiological characteristic of the tissue and can specifically reflect the characteristics of vascular lesions. In DSC, the post-processed acquired time series can be used to acquire perfusion maps with the above parameters. DCE can measure the hemodynamic properties of tissues, such as density, integrity, leakiness, and permeability of tissue vasculature, by obtaining continuous MRI from the pre- and post-intravenous injection of a CA $(58,61)$. To acquire quantitative DCE-MRI data, three main components of measurements are needed: 1) an original T1 map before contrast administration; 2) acquiring T1weighted images after CA injection at a proper temporal resolution; and 3) a method to evaluate the arterial input function (59). Compared with DSC-MRI, T1 DCE-MRI has a lower temporal resolution and is mainly used to reflect the density of microvessels.

Based on all aforementioned data, perfusion MRI plays an essential role in tumor treatment within clinical practice. The formation of increasing new blood vessels is essential to the growth of malignancy (73); as a result, $\mathrm{BV}$ and $\mathrm{BF}$ will rise correspondingly. In brain tumors, previous studies have shown that cerebral $\mathrm{BV}(\mathrm{CBV})$ and cerebral $\mathrm{BF}(\mathrm{CBF})$ are associated with predicting clinical outcomes, such as OS and PFS (62). A study in high-grade-glioma and low-grade-glioma patients indicated that $\mathrm{CBV}$ (the mean relative $\mathrm{CBV}=1.75$ ) correlates positively with disease progression (62). However, in clinical practice, the use of median CBV and CBF is limited because of highly heterogenous gliomas, resulting in low sensitivity and specificity of assessing efficacy. Additionally, it should be noticed that a tumor may display low-rise CBV. An increasing number of studies indicate that DCE-MRI may improve differential diagnosis, localization, tissue features, staging, and monitoring treatment response in neoplastic diseases $(60,70,115,116)$. In prostate cancer, previous studies demonstrate that DCE-MRI may be useful for delineating both tumors and surrounding normal tissues in the prostate gland with sensitivity of $59 \%-87 \%$ and specificity of $74 \%-84 \%(63,64,117)$. DCE could predict the volume change of radiation-induced parotid by evaluating individual microvascular perfusion and tissue diffusion rates in HNC patients, suggesting an adjustment of the treatment plan before RT $(17,65)$. In advanced cervical carcinoma, evidence illustrates that DCE is likely to provide a clinically useful biomarker for the prognosis based on pharmacokinetic analysis of DCE-MRI data $(118,119)$. Additionally, different levels of tumor hypoxia are common during RT but are not easily assessable in patients. In clinical practice, parameter $\mathrm{K}^{\text {trans }}$ is a potentially useful biomarker for tumor hypoxia, RT resistance, and metastasis in cancers $(66-69)$ as well as Ve $(66,69)$.

Although DSC and DCE have been relatively mature, there are still some limitations of parameter calculation in clinical practice. First, $\mathrm{CBV}$ and $\mathrm{CBF}$ are always changeable in any region of gliomas owing to circuitous vasculature and immature vascular structures, especially in high-grade gliomas $(71,72)$. Second, many factors may influence the leakiness of blood vessels, such as vascular permeability, BF, vascular lumen area, and even temperature (120-122). Therefore, $\mathrm{K}^{\text {trans }}$ and Ve value can be influenced easily by the above factors and not only reflect vessel permeability. A study conducted by Law et al. probably provides us with some insights into which a combination between DSC and DCE can significantly improve diagnostic accuracy and sensitivity (62).

\section{Blood Oxygenation Level-Dependent Functional MRI}

BOLD-fMRI signals provide real-time cerebral oxygen distribution under normal physiological conditions, based on local magnetic field properties resulting from a mismatch between local oxygen consumption caused by neuronal activity and increased CBF reactivity (85). BOLD signal has four parameters: onset time, time to peak, full width at half maximum (FWHM), and amplitude (86). The increase of local $\mathrm{CBF}$ causes a reduction in the local amount of deoxygenated hemoglobin generated by metabolism in response to neuronal activity, presenting signal enhancement (T2 and $\left.\mathrm{T} 2{ }^{*}\right)$ in related brain regions (100). Among these regions, transparent contrast relies on repeatedly averaging subtle differences of signal enhancement. Brain activation mapping using BOLD-fMRI is based on the prerequisite that there is a tight coupling between neuronal activity and hemodynamic changes (101). Deoxyhemoglobin in the blood vessels is regarded as an endogenous CA during the production of functional activation maps. Oxyhemoglobin contains an unpaired electron and is therefore diamagnetic. Deoxyhemoglobin contains four unpaired electrons and is a paramagnetic substance. The different concentrations of oxyhemoglobin and deoxyhemoglobin will cause local magnetic field inhomogeneity, leading to the difference in the signal on the image and then production of imaging.

Current clinical application is mainly used for the positioning of the functional cortical center, including vision, movement, and hearing. BOLD-fMRI has become a valuable tool for presurgical functional brain mapping. In surgery, BOLD-fMRI can guide the safest surgical trajectory between functionally viable brain tissue and the lesion. In particular, in brain tumor patients, who are often neurologically impaired, we should take patient preparation and neurobehavioral evaluation into special consideration when performing fMRI. BOLD-fMRI for preoperative planning allows for accurate risk assessment of surgery-related brain damage, such as postoperative motion, 
visual and somatosensory deficits, and intraoperative cortical stimulation (ICS) mapping, reducing surgical time (97) and need for further preoperative diagnostic studies (123). Moreover, BOLD-fMRI demonstrates an excellent concordance with ICS for motor mapping (87-90) and language mapping (91-93). Wang et al. and Pantelis et al. have demonstrated that the combination of BOLD-fMRI and DTI could be beneficial of marking and sparing OARs in radiation treatment planning, resulting in less radiation toxicity $(95,96)$. In addition, a study showed that BOLD-fMRI is a non-invasive technique that could explore hypoxia information by analyzing the correlations of the ${ }^{*} \mathrm{R}$ value and HIF-1 $\alpha$ (94).

Spatial resolution is one of the limitations of BOLD-fMRI, as flow increases in some of the larger arteries or veins feeding or draining large neuronal areas. The solution is to insert a "diffused" gradient pulse (corresponding to low b-values) into the MRI sequence; the largest vascular contribution in the BOLD signal (high $\mathrm{D}^{*}$ values are associated with fast flow) can be squeezed to improve the spatial resolution of the activation map $(98,99)$. In addition, neurovascular uncoupling is another key limitation that could affect the accuracy of BOLD-fMRI surrounding brain tumors, but combining an observed vasotask dependency with the BOLD signal analysis may partially overcome this shortcoming (101).

\section{Diffusion Tensor Imaging-MRI}

DTI-MRI is an MRI technique that can be used in vivo noninvasively to measure anisotropic diffusion of water molecules in various tissues, leading to producing neural tract images (74). Abnormalities in the fiber structure of the axonal (white matter) can be detected by DTI-MRI, which can model brain connectivity. Thus, it has been rapidly developed to implement RT of white matter disorders (77). At present, DTI-MRI had been extensively utilized for glioma researches. DTI parameters include $\mathrm{ADC}$ and fractional anisotropy (FA) values (74).

Price et al. showed that glioma cells are prone to invade tissue along the direction of white matter tracks (WMTs) (75). Another study by Krishnan et al. calculated routes of water diffusion from the primary tumor location to tumor progression location by using DTI-MRI in glioma patients. Meanwhile, this study also showed that the direction of elevated water diffusion may be a reliable indicator of routes of tumor progression (78), which is consistent with Price's study. Thus, DTI MRI would help localize and identify the possible microscopic disease and will help to delineate CTV more accurately. Also, some previous studies have proved that it may aid in the optimal delineation of biological CTV by incorporating DTI-MRI into RT planning while reducing the dose exposure to nearby function regions $(76,78-$ 81). A study by Conti et al. demonstrated that radiation dose exposure to OARs was decreased by up to $16.86 \%$ after the integration of functional neuroimaging as compared with their initial values (124). In addition, DTI-MRI can evaluate response to neoadjuvant chemotherapy in patients with breast cancer $(82,83)$.

In DTI, there are still some other technique defects, such as the distortion of the image because of an uneven magnetic field and poor display for smaller fiber bundles (84). However, DTI has been rapidly developed in nervous system diseases, with an extensive clinical prospect to optimize TV, predict prognosis, and better protect functional regions of the brain.

\section{THERAPEUTIC INDEX IN RADIATION THERAPY}

Conventional MRI already anatomically offers better soft tissue imaging in contrast to CT (125). However, it is not enough to provide high sensitivity and specificity delineation of TV due to a lack of functional indications. At the anatomic level, previous studies have demonstrated that functional imaging can provide a more accurate delineation of tumor TV base on better background contrast between tumor and normal tissue $(12,63$, $64,113,117)$. Accurately defining the boundaries between tumor and normal tissue gives rise to the increased distance between tumor and OARs in function imaging-guided IMRT (Figure 1A). Moreover, the increased distance is beneficial for imaging-guided dose escalation in $\mathrm{TV}$ and decreased dose exposure in OARs (Figures 1B, C). In addition to the clear anatomical display, we note that there are several concepts and advanced radiation techniques related to fMRI-based RT that have great potential to improve TI, including tumor hypoxia, dose painting, adaptive RT (ART), local recurrence, and MRguided linear accelerator (MR-LINAC). Among them, the integration of $\mathrm{AMRI}$ can provide TI benefits.

\section{Tumor Hypoxia}

Despite improvement in the accuracy of target delineation and radiation delivery due to advances in $\mathrm{RT}$ and imaging techniques, in-field recurrence remains the predominant local failure model (126), which may be explained by the fact that the PTV of the entire primary tumor and the involved lymph nodes is delivered with a homogenous radiation dose without considering the intratumoral heterogeneity. Heterogeneity is one of the inherent characteristics of tumors, which is mainly manifested in the heterogeneity of intracellular and molecular biological features (including glucose metabolism, cell proliferation, hypoxia, epithelial growth factor receptor (EGFR) expression, and choline metabolism, etc.) (127). Tumor hypoxia is fairly common in RT due to abnormal vessel structures. Hypoxia is highly associated with poor prognosis because oxygen-deprived cells are strongly resistant to chemoradiotherapy, which leads to failure. Therefore, identifying and quantifying tumor hypoxia are important and necessary for improving TI in RT treatment. Numerous studies have shown that $\mathrm{fMRI}$ is an attractive option to identify, quantify, and spatially map hypoxic areas prior to therapy, as well as to track hypoxia changes during radiation $(51,66-69,94)$, resulting in guiding increased radiation doses to hypoxic RT-resistant areas.

\section{Dose Painting}

The concept of dose painting has been proposed to improve local control through increasing the dose to a segment of intra-tumor radiation-resistant while decreasing the dose to a radiosensitive segment based on fMRI (126). IMRT can deliver non-uniform 
dose distribution, but how to follow the region of interest (ROI) remains unknown. Therefore, biological/molecular information derived from fMRI may be a help to identify and track tumor hypoxia, proliferation, and other ROIs. The fMRI-based dose painting opens a new era called "biological conformality." Previous studies showed that fMRI-guided imaging could help radiation dose boost in certain areas by means of dose painting in tumor target (128-131) while sparing OARs (128-132). According to the quantitative parameter maps from functional imaging $(126,133)$, the radiation dose can be spatially redistributed in the target area and OARs. The dose mapping seems to be more reasonable than surgery, a way of all-ornothing therapy, as intratumoral heterogeneity is a natural feature. DCE-MRI can also be used for dose painting based on its ability to display microvasculature permeability and BF, which is associated with the tumor's oxygenation (134-137). DWI can reflect areas with a higher tumor burden $(138,139)$ and with radiation resistance $(14,15)$. MRSI possesses the ability to monitor tumor metabolism $(140,141)$ and is also useful for dose painting.

\section{Adaptive Radiation Therapy}

In clinical practice, the target for RT is dynamic. It changes over a time frame, including position, size, shape, and biology. ART strategies systematically track variations in targets and adjacent structures to timely inform treatment-plan modification during RT. Monitoring variations is necessary because a single pretreatment plan is inadequate to reflect the actual dose distribution on the tumor and its surroundings during RT (142). This technology allows for increasing doses delivered to tumors while simultaneously limiting dose exposure to the normal structures. MRI-guided ART provided both personalized geometric and biological adaption (143). Bladder cancer is well suitable for ART since the bladder has large interfractional changes and intra-fractional motion $(144,145)$. MRIguided adaptive brachytherapy in cervical cancer $(146,147)$ and primary vaginal cancer (148) results in effective and stable longterm local control at all stages of cervical cancer, while decreasing severe radiation-induced morbidity. Similarly, promising results are also observed in liver tumors (149), prostate cancer (150), and unresectable primary malignancies of the abdomen. It seems like MRI-guided ART is more suitable for highly radiosensitive tumors with large motion changes and volume changes over the course of RT.

\section{Local Recurrence}

Despite advances in RT and imaging techniques, in-field recurrence remains a common failure model. Recurrent lesions are a treatment challenge because of RT resistance and radiation dose limitation to surrounding normal tissues. The ability of fMRI to differentiate tumor recurrence to post-radiation treatment effects, including pseudoprogression and radiation necrosis, provides assistance in reirradiation settings in patients treated after primary chemoradiotherapy $(23,24)$. ADC values for radiation necrosis were found to be higher than for recurrence in some studies; however, the reported values are inconsistent and may be explained by technical factors (151).
A study by Xu et al. (152) using DTI showed that the mean ADC ratios for radiation necrosis in recurrent tumors were 1.62 and 1.34. An alternative to DTI is that it favors tumor recurrence over radiation necrosis when diffusion restriction is present on the ADC image, which does not show diffusion restriction. DCEMRI perfusion measures $\mathrm{CBV}$ and $\mathrm{CBF}$, which can be accurately measured in the presence of a blood-brain barrier breakdown (151). A study by Larsen et al. (153) measured CBV in patients with MRI contrast-enhanced. They found that lesion regression shows low CBV (less than $1.7 \mathrm{ml} / 100 \mathrm{~g}$ ), while lesion progression shows high CBV ( $>2.2 \mathrm{ml} / 100 \mathrm{~g})$. Therefore, Larsen et al. concluded that an absolute CBV threshold of $2.0 \mathrm{ml} / 100 \mathrm{~g}$ can detect lesion degeneration or progression, with a reported sensitivity and specificity of $100 \%$. Several studies have shown that patients with tumor recurrence have higher $\mathrm{Cho} / \mathrm{Cr}$ and Cho/NAA values than patients with radiation necrosis (151, 154). In addition, fMRI can predict tumor aggressiveness and early treatment response, with the assistance of deciding early therapy intervention and improving the prognosis $(17,23,24)$.

\section{MR-Guided Linear Accelerator}

In recent years, with the advancement of MR-guided RT, accurate radiation is facing new challenges and prospects. MRLINAC is a new technology and the first machine in the world to combine radiation equipment (such as a linear accelerator or ${ }^{60} \mathrm{Co}$ sources) and high-resolution MRI (155). The key benefits of MR-LINAC are that it can record MR images for every fraction and use these for daily plan adaptation. During the radiation treatment of the tumor, the radiation beams are accurately located in and destroy tumors, while avoid radiating and harming the nearby healthy tissues. Currently, MR-LINAC has been applied in various tumors, including pancreatic cancer, prostate cancer, and liver cancer (156-159). To date, MR-LINAC seems to be the most efficient method to optimize the TI of RT in cancer treatment. Combining MRI with the most accurate RT techniques, such as proton therapy, will be our ultimate goal (160). However, prolonged treatment times, patient tolerance, and high cost are the major obstacles. At present, related studies on MR-LINAC are still at an early stage with sparse clinical evidence, despite interesting potential.

\section{CHALLENGES AND PROSPECTS}

Although the use of quantitative imaging was studied since the early 1990s in RT (125), there are still significant barriers to its widespread use in clinical practice. Excitingly, with the development of fMRI techniques, some prospects are inspiring.

\section{Challenges of Functional MRI for Radiation Therapy}

From the object technology perspective, inconsistent imaging is commonly produced by different vendors, machines, and imaging protocols. However, quantitative imaging in RT is not a simple substitute for quantitative imaging in radiology. For example, in an RT scan, the patient's position needs to be as 
similar as possible to the treatment setting. However, it is not easy to accomplish this in many institutions because of various policies and management. In addition, robust calibration for biomarkers is still a big challenge, as the current quantitative imaging technique needs one or multiple measurable parameters to produce a voxel, leading to in worse signal-to-noise ratio (SNR) and greater voxels than traditional imaging (107). Last but not least, when applying different imaging techniques together, it is difficult for clinicians to interpret multiparametric functional images with transparently conflicting information; for example, the overlap is largely restricted in the area identified by DWI and DCE-MRI simultaneously.

On the artificial perspective, currently, delineation of most tumors and OARs are still through manual procedures, in which the TV is determined by a radiation oncologist and a radiologist together on the basis of clinical information and images. Therefore, differences in which different spectators have various definitions in anatomic features of OAR boundary may cause inconsistency in the OAR definition. Moreover, errors caused by mistakenly missing or adding parts can give rise to inaccurate delineation in OARs. Finally, a small part of oncologists, particularly those in rural areas, do not receive sufficient training and clear instructions which leads to discrepancies in the anatomic definition of OARs.

From the economic perspective, compared with conventional MRI, fMRI is more expensive. This is because the application of fMRI requires higher machine costs. Some studies speculate that models combined with multiparametric MRI (mpMRI) have advantages of cost-effectiveness, but their findings are based on several a priori assumptions for every model (161-165). Therefore, any change in the selected criteria might result in a major change in the cost and, consequently, in the conclusions. Notably, to date, the evidence for the use of mpMRI to consider further biopsy is at best based on minimal clinical data $(166,167)$. Furthermore, such a policy is still under observation, as almost all publications are related only to systematic biopsy. There are several limitations associated with the widespread utilization of mpMRI in clinical practice. First, low-quality mpMRI is still a major issue. Surprisingly, the initial cost of repeat low-quality mpMRI is very common but not mentioned. Most importantly, there are no standardized principles to evaluate mpMRI progression in patients on AS. For example, how should we assess the lesion status in Prostate Imaging-Reporting? Is it an increase in tumor size, if so, how about the threshold? Finally, above all, evidence is mainly from small studies and extrapolation of various strategies such as enlarging the merit of initial mpMRI for biopsy.

\section{Prospects of Functional MRI for Radiation Therapy}

According to the above challenges, there are some relative solutions. To acquire consistent and continuous images, we suggest that it would be better if patients are willing to receive a complete examination under same conditions. To analyze the conflicting information, some researchers suggest defining the area identified by two imaging approaches as gross tumor volume (GTV); the areas indicated by only one of the imaging techniques can be defined as CTV with high risk. To reduce inter-observer variability of OAR delineation, an automatically delineated system might be recommended in the future. Also, standardized training should be publicized widely.

Concerning cost-effectiveness improvement, the growing body of evidence demonstrates that fMRI may bring cost-effectiveness in prostate cancer. In contrast to transrectal ultrasoundguided biopsy (TRUS) alone, the use of mpMRI to select patients for repeat biopsy holds fewer biopsies and lower cost, despite that a few cancers are being missed, but further research is needed to determine whether missed cancers represent clinically significant tumors (168). Another study showed that an mpMRI-first strategy and then TRUS are cost-effective to diagnose clinically significant prostate cancer (169). In patients with low-risk cancer, overtreatment will lead to adverse effects and unnecessary costs (170). Active surveillance (AS) program, which contains digital rectal examination (DRE), prostate-specific antigen (PSA), and standard repeated 12-core TRUS, is currently recommended for avoiding overtreatment (170). However, the standard AS has some limitations, including missing high-risk tumors and performing unnecessary biopsies. The strategy of using mpMRI combined with limited MR-guided TRUS can improve quality of life and greatly reduce cost in low-risk prostate cancer patients during follow-up (170). Adequate data are further needed from large randomized prospective cohorts in the future.

In terms of some new insights or techniques, based on the above, the application of fMRI to guide dose painting and ART to detect tumor hypoxia area and postoperative local recurrence, in combination with MR-LINAC, has led to some promising findings. Despite the lack of a uniform measurement standard, we expect to further explore the function of fMRI in improving TI through large-scale randomized clinical studies.

\section{CONCLUSION}

Incorporating functional imaging techniques into RT planning has big potential to improve $\mathrm{TI}$ in RT via different mechanisms. Functional imaging possesses potential advantages, as follows. First, quantitative imaging may provide superior contour and visibility between tumors and normal tissues, with the benefit of dose escalation in TV and dose reduction in OARs, with the promising potential for guiding de-escalation in oropharyngeal carcinoma patients $(171,172)$. Second, quantitative imaging may be a potent toxicity prediction tool during RT. These can give us a clinical indication for precaution. Third, the combination of different functional imaging techniques may make up for shortcomings that exist in single imaging. We believe that it is worthwhile to overcome the above challenges and explore larger, multicenter, randomized clinical studies on quantitative imaging in RT.

\section{AUTHOR CONTRIBUTIONS}

KY and ML: study design. KY, ML, and QZ: data collection. KY and ML: data interpretation and writing. All authors contributed to the article and approved the submitted version. 


\section{REFERENCES}

1. Wilson J, Hammond E, Higgins G, Petersson K. Corrigendum: Ultra-High Dose Rate (FLASH) Radiotherapy: Silver Bullet or Fool's Gold? Front Oncol (2010) 10: 00210. doi: 10.3389/fonc.2020.00210

2. Lin SH, Hobbs BP, Verma V, Tidwell RS, Smith GL, Lei X, et al. Randomized Phase IIB Trial of Proton Beam Therapy Versus Intensity-Modulated Radiation Therapy for Locally Advanced Esophageal Cancer. J Clin Oncol (2020) 38(14):1569-79. doi: 10.1200/JCO.19.02503

3. Lecchi M, Piero F, Federica E, Roberto O, Giovanni L, et al. Current Concepts on Imaging in Radiotherapy. Eur J Nucl Med Mol Imaging (2008) 35(4):821-37. doi: 10.1007/s00259-007-0631-y

4. Press RH, Shu HG, Shim H, Mountz JM, Kurland BF, Wahl RL, et al. The Use of Quantitative Imaging in Radiation Oncology: A Quantitative Imaging Network (QIN) Perspective. Int J Radiat Oncol Biol Phys (2018) 102(4):1219-35. doi: 10.1016/j.ijrobp.2018.06.023

5. Le BD, Breton E, Lallemand D, Aubin ML, Vignaud J, Laval-Jeantet M. Separation of Diffusion and Perfusion in Intravoxel Incoherent Motion MR Imaging. Radiology (1988) 168(2):497-505. doi: 10.1148/radiology. 168.2.3393671

6. Bammer R. Basic Principles of Diffusion-Weighted Imaging. Eur J Radiol (2003) 45(3):169-84. doi: 10.1016/s0720-048x(02)00303-0

7. Zhang X, Fu Z, Gong G, Wei H, Duan J, Chen Z, et al. Implementation of Diffusion-Weighted Magnetic Resonance Imaging in Target Delineation of Central Lung Cancer Accompanied With Atelectasis in Precision Radiotherapy. Oncol Lett (2017) 14(3):2677-82. doi: 10.3892/ol.2017.6479

8. Dirix P, Vandecaveye V, Keyzer DF, Beeck DOK, Poorten VV, Delaere P, et al. Diffusion-Weighted MRI for Nodal Staging of Head and Neck Squamous Cell Carcinoma Impact on Radiotherapy Planning. Int J Radiat Oncol Biol Phys (2010) 76(3):761-6. doi: 10.1016/j.ijrobp.2009.02.068

9. Vandecaveye V, De KF, Vander PV, Dirix P, Verbeken E, Nuyts P, et al. Head and Neck Squamous Cell Carcinoma: Value of Diffusion-Weighted MR Imaging for Nodal Staging. Radiology (2009) 251(1):134-46. doi: 10.1148/radiol.2511080128

10. Wu LM, Xu JR, Liu MJ, Zhang XF, Hua J, Zheng J, et al. Value of Magnetic Resonance Imaging for Nodal Staging in Patients With Head and Neck Squamous Cell Carcinoma: A Meta-Analysis. Acad Radiol (2012) 19(3):33140. doi: 10.1016/j.acra.2011.10.027

11. Regini F, Gourtsoyianni S, Cardoso De Melo R, Charles-Edwards GD, Griffin N, Parikh J, et al. Rectal Tumour Volume (GTV) Delineation Using T2-Weighted and Diffusion-Weighted MRI: Implications for Radiotherapy Planning. Eur J Radiol (2014) 83(5):768-72. doi: 10.1016/j.ejrad.2014.02.007

12. Rosa C, Caravatta L, Delli Pizzi A, Di Tommaso M, Cianci R, Gasparini L, et al. Reproducibility of Rectal Tumor Volume Delineation Using DiffusionWeighted MRI: Agreement on Volumes Between Observers. Cancer Radiother (2019) 23(3):216-21. doi: 10.1016/j.canrad.2018.10.004

13. Burbach JP, Kleijnen JP, Reerink O, Seravalli E, Philippens ME, Schakel T, et al. Inter-Observer Agreement of MRI-Based Tumor Delineation for Preoperative Radiotherapy Boost in Locally Advanced Rectal Cancer. Radiother Oncol (2016) 118(2):399-407. doi: 10.1016/j.radonc.2015.10.030

14. Vandecasteele K, Tummers P, Van BM, De VP, Vercauteren T, De GW, et al. EXclusion of non-Involved Uterus From the Target Volume (EXIT-Trial): An Individualized Treatment for Locally Advanced Cervical Cancer Using Modern Radiotherapy and Imaging Techniques. BMC Cancer (2018) 18 (1):898. doi: 10.1186/s12885-018-4800-0

15. Atwell D, Elks J, Cahill K, Hearn N, Vignarajah D, Lagopoulos J, et al. A Review of Modern Radiation Therapy Dose Escalation in Locally Advanced Head and Neck Cancer. Clin Oncol (R Coll Radiol) (2020) 32(5):330-41. doi: 10.1016/j.clon.2019.12.004

16. Loimu V, Seppälä T, Kapanen M, Tuomikoski L, Nurmi H, Mäkitie A, et al. Diffusion-Weighted Magnetic Resonance Imaging for Evaluation of Salivary Gland Function in Head and Neck Cancer Patients Treated With IntensityModulated Radiotherapy. Radiother Oncol (2017) 122(2):178-84. doi: 10.1016/j.radonc.2016.07.008

17. Marzi S, Farneti A, Vidiri A, Di Giuliano F, Marucci L, Spasiano F, et al. Radiation-Induced Parotid Changes in Oropharyngeal Cancer Patients: The Role of Early Functional Imaging and Patient-/Treatment-Related Factors. Radiat Oncol (2018) 13(1):189. doi: 10.1186/s13014-018-1137-4
18. Yoon MA, Hong SJ, Lee CH, Kang CH, Ahn KS, Kim BH. Intravoxel Incoherent Motion (IVIM) Analysis of Vertebral Bone Marrow Changes After Radiation Exposure From Diagnostic Imaging and Interventional Procedures. Acta Radiol (2017) 58(10):1260-8. doi: 10.1177/0284185116688380

19. Ellingson BM, Sahebjam S, Kim HJ, Pope WB, Harris RJ, Woodworth DC, et al. Cloughesy, Pretreatment ADC Histogram Analysis is a Predictive Imaging Biomarker for Bevacizumab Treatment But Not Chemotherapy in Recurrent Glioblastoma. AJNR Am J Neuroradiol (2014) 35(4):673-9. doi: 10.3174/ajnr.A3748

20. Pope W, Kim H, Huo J, Alger J, Brown M, Gjertson D, et al. Recurrent Glioblastoma Multiforme: ADC Histogram Analysis Predicts Response to Bevacizumab Treatment. Radiology (2009) 252(1):182-9. doi: 10.1148/ radiol.2521081534

21. Pope W, Qiao X, Kim H, Lai A, Nghiemphu P, Xue X, et al. Cloughesy, Apparent Diffusion Coefficient Histogram Analysis Stratifies ProgressionFree and Overall Survival in Patients With Recurrent GBM Treated With Bevacizumab: A Multi-Center Study. J Neurooncol (2012) 108(3):491-8. doi: 10.1007/s11060-012-0847-y

22. Rahman R, Hamdan A, Zweifler R, Jiang H, Norden A, Reardon D, Reardon $D$, et al. Histogram Analysis of Apparent Diffusion Coefficient Within Enhancing and Nonenhancing Tumor Volumes in Recurrent Glioblastoma Patients Treated With Bevacizumab. J Neurooncol (2014) 119(1):149-58. doi: 10.1007/s11060-014-1464-8

23. Liu ZC, Yan LF, Hu YC, Sun YZ, Tian Q, Nan HY, et al. Combination of IVIM-DWI and 3D-ASL for Differentiating True Progression From Pseudoprogression of Glioblastoma Multiforme After Concurrent Chemoradiotherapy: Study Protocol of a Prospective Diagnostic Trial. BMC Med Imaging (2017) 17(1):10. doi: 10.1186/s12880-017-0183-y

24. Suh CH, Kim HS, Jung SC, Choi CG, Kim SJ. Multiparametric MRI as a Potential Surrogate Endpoint for Decision-Making in Early Treatment Response Following Concurrent Chemoradiotherapy in Patients With Newly Diagnosed Glioblastoma: A Systematic Review and Meta-Analysis. Eur Radiol (2018) 28(6):2628-38. doi: 10.1007/s00330-017-5262-5

25. Koh DM, Collins DJ, Orton MR. Intravoxel Incoherent Motion in Body Diffusion-Weighted MRI: Reality and Challenges. AJR Am J Roentgenol (2011) 196(6):1351-61. doi: 10.2214/AJR.10.5515

26. Liang J, Li J, Li Z, Meng T, Chen J, Ma W, et al. Differentiating the Lung Lesions Using Intravoxel Incoherent Motion Diffusion-Weighted Imaging: A MetaAnalysis. BMC Cancer (2020) 20(1):799. doi: 10.1186/s12885-020-07308-z

27. Le Bihan D, Breton E, Lallemand D, Grenier P, Cabanis E, Laval-Jeantet M. MR Imaging of Intravoxel Incoherent Motions: Application to Diffusion and Perfusion in Neurologic Disorders. Radiology (1986) 161(2):401-7. doi: 10.1148/radiology.161.2.3763909

28. Wang CC, Dong HB, Ding F, Li YD, Wang GY, Ding HX. Quantitative Evaluation of Intravoxel Incoherent Motion Diffusion-Weighted Imaging and Three-Dimensional Arterial Spin Labeling in Ki-67 Labeling Index and Grading of Brain Gliomas. Zhonghua Yi Xue Za Zhi (2019) 99(5):338-42. doi: $10.3760 / \mathrm{cma}$.j.issn.0376-2491

29. Wang C, Dong H. Ki-67 Labeling Index and the Grading of Cerebral Gliomas by Using Intravoxel Incoherent Motion Diffusion-Weighted Imaging and ThreeDimensional Arterial Spin Labeling Magnetic Resonance Imaging. Acta Radiol (2020) 61(8):1057-63. doi: 10.1177/0284185119891694

30. Cen D, Hu W, Wang X, Wu X. Re: Identification of Preoperative Magnetic Resonance Imaging Features Associated With Positive Resection Margins in Breast Cancer? . Korean J Radiol (2019) 20(6):999-1000. doi: 10.3348/kjr.2019.0044

31. Youn I, Choi S, Choi YJ, Moon JH, Park HJ, Ham SY, et al. Contrast Enhanced Digital Mammography Versus Magnetic Resonance Imaging for Accurate Measurement of the Size of Breast Cancer. Br J Radiol (2019) 92 (1098):20180929. doi: 10.1259/bjr.20180929

32. Ai Z, Han Q, Huang Z, Wu J, Xiang Z. The Value of Multiparametric Histogram Features Based on Intravoxel Incoherent Motion DiffusionWeighted Imaging (IVIM-DWI) for the Differential Diagnosis of Liver Lesions. Ann Transl Med (2020) 8(18):1128. doi: 10.21037/atm-20-5109

33. Wang M, Li X, Zou J, Chen X, Chen S, Xiang W. Evaluation of Hepatic Tumors Using Intravoxel Incoherent Motion Diffusion-Weighted MRI. Med Sci Monit (2016) 22:702-9. doi: 10.12659/msm.895909

34. Mao X, Zou X, Yu N, Jiang X, Du J. Quantitative Evaluation of Intravoxel Incoherent Motion Diffusion-Weighted Imaging (IVIM) for Differential Diagnosis and Grading Prediction of Benign and Malignant Breast 
Lesions. Med (Baltimore) (2018) 97(26):e11109. doi: 10.1097/ MD.0000000000011109

35. Yoon JH, Lee JM, Yu MH, Kiefer B, Han JK, Choi BI. Evaluation of Hepatic Focal Lesions Using Diffusion-Weighted MR Imaging: Comparison of Apparent Diffusion Coefficient and Intravoxel Incoherent Motion-Derived Parameters. J Magn Reson Imaging (2014) 39(2):276-85. doi: 10.1002/ jmri.24158

36. Sun $\mathrm{H}$, Xu Y, Song A, Shi K, Wang W. Intravoxel Incoherent Motion MRI of Rectal Cancer: Correlation of Diffusion and Perfusion Characteristics With Prognostic Tumor Markers. AJR Am J Roentgenol (2018) 210(4):W139w147. doi: 10.2214/AJR.17.18342

37. Cao Y, Sundgren PC, Tsien CI, Chenevert TT, Junck L. Physiologic and Metabolic Magnetic Resonance Imaging in Gliomas. J Clin Oncol (2006) 24 (8):1228-35. doi: 10.1200/ JCO.2005.04.7233

38. Jansen JFA, Backes WH, Nicolay K, Kooi ME. 1h MR Spectroscopy of the Brain: Absolute Quantification of Metabolites. Radiology (2006) 240(2):31832. doi: $10.1148 /$ radiol.2402050314

39. Zhu H, Barker PB. MR Spectroscopy and Spectroscopic Imaging of the Brain. Methods Mol Biol (2011) 711:203-26. doi: 10.1007/978-161737-992-5_9

40. Moffett JR, Ross B, Arun P, Madhavarao CN, Namboodiri AM. NAcetylaspartate in the CNS: From Neurodiagnostics to Neurobiology. Prog Neurobiol (2007) 81(2):89-131. doi: 10.1016/j.pneurobio.2006.12.003

41. Ratai EM, Zhang Z, Fink J, Muzi M, Hanna L, Greco E, et al. ACRIN 6684: Multicenter, Phase II Assessment of Tumor Hypoxia in Newly Diagnosed Glioblastoma Using Magnetic Resonance Spectroscopy. PloS One (2018) 13 (6):e0198548. doi: 10.1371/journal.pone.0198548

42. Amstalden van Hove E, Blackwell T, Klinkert I, Eijkel G, Heeren R, Glunde K. Multimodal Mass Spectrometric Imaging of Small Molecules Reveals Distinct Spatio-Molecular Signatures in Differentially Metastatic Breast Tumor Models. Cancer Res (2010) 70(22):9012-21. doi: 10.1158/0008-5472.CAN-10-0360

43. Chen WS, Li JJ, Hong L, Xing ZB, Wang F, Li CQ. Diagnostic Value of Magnetic Resonance Spectroscopy in Radiation Encephalopathy Induced by Radiotherapy for Patients With Nasopharyngeal Carcinoma: A MetaAnalysis. BioMed Res Int (2016) 2016:5126074. doi: 10.1155/2016/5126074

44. Ramazan A, Demircioglu O, Ugurlu U, Kaya H, Aribal E. Efficacy of Single Voxel 1H MR Spectroscopic Imaging at 3T for the Differentiation of Benign and Malign Breast Lesions. Clin Imaging (2016) 40(5):831-6. doi: 10.1016/ j.clinimag.2016.03.007

45. Casciani E, Polettini E, Bertini L, Emiliozzi P, Amini M, Pansadoro V, et al. Prostate Cancer: Evaluation With Endorectal MR Imaging and Three-Dimensional Proton MR Spectroscopic Imaging. Radiol Med (2004) 108(5-6):530-41.

46. Benzakoun J, Robert C, Legrand L, Pallud J, Meder JF, Oppenheim C, et al. Anatomical and Functional MR Imaging to Define Tumoral Boundaries and Characterize Lesions in Neuro-Oncology. Cancer Radiother (2020) 24 (5):453-62. doi: 10.1016/j.canrad.2020.03.005

47. Cordova JS, Shu HK, Liang Z, Gurbani SS, Cooper LA, Holder CA, et al. Whole-Brain Spectroscopic MRI Biomarkers Identify Infiltrating Margins in Glioblastoma Patients. Neuro Oncol (2016) 18(8):1180-9. doi: 10.1093/ neuonc/now036

48. Diamandis E, Gabriel CPS, Wurtemberger U, Guggenberger K, Urbach H, Staszewski O, et al. MR-Spectroscopic Imaging of Glial Tumors in the Spotlight of the 2016 WHO Classification. J Neurooncol (2018) 139(2):43140. doi: 10.1007/s11060-018-2881-x

49. Narayana A, Chang J, Thakur S, Huang W, Kowalski A, Perera G, et al. Use of MR Spectroscopy and Functional Imaging in the Treatment Planning of Gliomas. Br J Radiol (2007) 80(953):347-54. doi: 10.1259/bjr/65349468

50. Chang J, Thakur SB, Huang W, Narayana A. Magnetic Resonance Spectroscopy Imaging (MRSI) and Brain Functional Magnetic Resonance Imaging (fMRI) for Radiotherapy Treatment Planning of Glioma. Techol Cander Res Treat (2008) 7(5):349-62.

51. Jiang L, Greenwood TR, Artemov D, Raman V, Winnard PTJr., Heeren RM, et al. Localized Hypoxia Results in Spatially Heterogeneous Metabolic Signatures in Breast Tumor Models. Neoplasia (2012) 14(8):732-41. doi: 10.1593/neo.12858

52. Pirzkall A, McKnight TR, Graves EE, Carol MP, Sneed PK, Wara WW, et al. MRSpectroscopy Guided Target Delineation for High-Grade Gliomas. Int J Radiat Oncol Biol Phys (2001) 50(4):915-28. doi: 10.1016/s0360-3016(01)01548-6
53. Deviers A, Ken S, Filleron T, Rowland B, Laruelo A, Catalaa I, et al. Evaluation of the Lactate-to-N-Acetyl-Aspartate Ratio Defined With Magnetic Resonance Spectroscopic Imaging Before Radiation Therapy as a New Predictive Marker of the Site of Relapse in Patients With Glioblastoma Multiforme. Int J Radiat Oncol Biol Phys (2014) 90(2):385-93. doi: 10.1016/ j.ijrobp.2014.06.009

54. Croteau D, Scarpace L, Hearshen D, Gutierrez J, Fisher JL, Rock JP, et al. Correlation Between Magnetic Resonance Spectroscopy Imaging and ImageGuided Biopsies: Semiquantitative and Qualitative Histopathological Analyses of Patients With Untreated Glioma. Neurosurgery (2001) 49 (2):823-9. doi: 10.1097/00006123-200110000-00008

55. Rock J, Hearshen D, Scarpace L, Croteau D, Gutierrez J, Fisher J, et al. Correlations Between Magnetic Resonance Spectroscopy and Image-Guided Histopathology, With Special Attention to Radiation Necrosis. Neurosurgery (2002) 51(4):912-9. doi: 10.1097/00006123-200210000-00010

56. Verma N, Cowperthwaite MC, Burnett MG, Markey MK. Differentiating Tumor Recurrence From Treatment Necrosis: A Review of NeuroOncologic Imaging Strategies. Neuro Oncol (2013) 15(5):515-34. doi: $10.1093 /$ neuonc/nos307

57. Gurbani SS, Schreibmann E, Maudsley AA, Cordova JS, Soher BJ, Poptani H, et al. A Convolutional Neural Network to Filter Artifacts in Spectroscopic Magnetic Resonance Imaging. Magn Reson Med (2018) 80(5):1765-75. doi: $10.1002 / \mathrm{mrm} .27166$

58. Tofts PS, Brix G, Buckley DL, Evelhoch JL, Henderson E, Knopp MV, et al. Estimating Kinetic Parameters From Dynamic Contrast-Enhanced T(1)Weighted MRI of a Diffusable Tracer: Standardized Quantities and Symbols. J Magn Reson Med (1999) 10(3):223-32. doi: 10.1002/(sici)1522-2586 (199909) 10:3<223::aid-jmri2>3.0.co;2-s

59. Teo QQ, Thng CH, Koh TS, Ng QS. Dynamic Contrast-Enhanced Magnetic Resonance Imaging: Applications in Oncology. Clin Oncol (R Coll Radiol) (2014) 26(10):e9-20. doi: 10.1016/j.clon.2014.05.014

60. Kargar S, Borisch EA, Froemming AT, Kawashima A, Mynderse LA, Stinson EG, et al. Robust and Efficient Pharmacokinetic Parameter non-Linear Least Squares Estimation for Dynamic Contrast Enhanced MRI of the Prostate. Magn Reson Imaging (2018) 48:50-61. doi: 10.1016/j.mri.2017.12.021

61. Cao Y. The Promise of Dynamic Contrast-Enhanced Imaging in Radiation Therapy. Semin Radiat Oncol (2011) 21(1):147-56. doi: 10.1016/ j.semradonc.2010.11.001

62. Law M, Young RJ, Babb JS, Peccerelli N, Chheang S, Gruber ML, et al. Gliomas: Predicting Time to Progression or Survival With Cerebral Blood Volume Measurements at Dynamic Susceptibility-Weighted ContrastEnhanced Perfusion MR Imaging. Radiology (2008) 247(2):490-8. doi: $10.1148 /$ radiol.2472070898

63. Li C, Chen M, Li S, Zhao X, Zhang C, Liu M, et al. Diffusion Imaging of the Prostate at 3.0 Tesla. Acta Radiol (2011) 52(7):813-7. doi: 10.1258/ ar.2011.100487

64. Futterer JJ, Heijmink SW, Scheenen TW, Veltman J, Huisman HJ, Vos P, et al. Prostate Cancer Localization With Dynamic Contrast-Enhanced MR Imaging and Proton MR Spectroscopic Imaging. Radiology (2006) 241 (2):449-58. doi: 10.1148/radiol.2412051866

65. Zhou N, Chu C, Dou X, Li M, Liu S, Zhu L, et al. Early Evaluation of Irradiated Parotid Glands With Intravoxel Incoherent Motion MR Imaging: Correlation With Dynamic Contrast-Enhanced MR Imaging. BMC Cancer (2016) 16(1):865. doi: 10.1186/s12885-016-2900-2

66. Klaassen R, Gurney-Champion OJ, Wilmink JW, Besselink MG, Engelbrecht MRW, Stoker J, et al. Repeatability and Correlations of Dynamic Contrast Enhanced and T2* MRI in Patients With Advanced Pancreatic Ductal Adenocarcinoma. Magn Reson Imaging (2018) 50:1-9. doi: 10.1016/ j.mri.2018.02.005

67. Ellingsen C, Hompland T, Galappathi K, Mathiesen B, Rofstad EK. DCEMRI of the Hypoxic Fraction, Radioresponsiveness, and Metastatic Propensity of Cervical Carcinoma Xenografts. Radiother Oncol (2014) 110 (2):335-41. doi: 10.1016/j.radonc.2013.10.018

68. Hauge A, Gaustad JV, Huang R, Simonsen TG, Wegner CS, Andersen LMK, et al. DCE-MRI and Quantitative Histology Reveal Enhanced Vessel Maturation But Impaired Perfusion and Increased Hypoxia in Bevacizumab-Treated Cervical Carcinoma. Int J Radiat Oncol Biol Phys (2019) 104(3):666-76. doi: 10.1016/j.ijrobp.2019.03.002 
69. Ovrebø KM, Ellingsen C, Galappathi K, Rofstad EK. Dynamic ContrastEnhanced Magnetic Resonance Imaging of the Metastatic Potential of Melanoma Xenografts. Int J Radiat Oncol Biol Phys (2012) 83(1):e121-7. doi: 10.1016/j.ijrobp.2011.12.019

70. Bonekamp D, Macura KJ. Dynamic Contrast-Enhanced Magnetic Resonance Imaging in the Evaluation of the Prostate. Top Magn Reson Imaging (2008) 19(6):273-84. doi: 10.1097/RMR.0b013e3181aacdc2

71. Zaca D, Hua J, Pillai JJ. Cerebrovascular Reactivity Mapping for Brain Tumor Presurgical Planning. World J Clin Oncol (2011) 2(7):289-98. doi: 10.5306/wjco. v2.i7.289

72. Jain RK, Carmeliet P. SnapShot: Tumor Angiogenesis. Cell (2012) 149 (6):1408-8.e.1. doi: 10.1016/j.cell.2012.05.025

73. Thomas MA, Nagarajan R, Huda A, Margolis D, Sarma MK, Sheng K, et al. Multidimensional MR Spectroscopic Imaging of Prostate Cancer In Vivo. NMR BioMed (2014) 27(1):53-66. doi: 10.1002/nbm.2991

74. Shaikh S, Kumar A, Bansal A. Diffusion Tensor Imaging: An Overview. Neurol India (2018) 66(6):1603-11. doi: 10.4103/0028-3886.246233

75. Price SJ, Jena R, Burnet NG, Hutchinson PJ, Dean AF, Pena A, et al. Improved Delineation of Glioma Margins and Regions of Infiltration With the Use of Diffusion Tensor Imaging: An Image-Guided Biopsy Study. AJNR Am J Neuroradiol (2006) 27(9):1969-74.

76. Berberat J, McNamara J, Remonda L, Bodis S, Rogers S. Diffusion Tensor Imaging for Target Volume Definition in Glioblastoma Multiforme. Strahlenther Onkol (2014) 190(10):939-43. doi: 10.1007/s00066-014-0676-3

77. Hagmann P, Jonasson L, Maeder P, Thiran JP, Wedeen VJ, Meuli R. Understanding Diffusion MR Imaging Techniques: From Scalar DiffusionWeighted Imaging to Diffusion Tensor Imaging and Beyond. Radiographics (2006) 26 Suppl 1:S205-23. doi: 10.1148/rg.26si065510

78. Krishnan AP, Asher IM, Davis D, Okunieff P, O'Dell WG. Evidence That MR Diffusion Tensor Imaging (Tractography) Predicts the Natural History of Regional Progression in Patients Irradiated Conformally for Primary Brain Tumors. Int J Radiat Oncol Biol Phys (2008) 71(5):1553-62. doi: 10.1016/j.ijrobp.2008.04.017

79. Jensen MB, Guldberg TL, Harboll A, Lukacova S, Kallehauge JF. Diffusion Tensor Magnetic Resonance Imaging Driven Growth Modeling for Radiotherapy Target Definition in Glioblastoma. Acta Oncol (2017) 56 (11):1639-43. doi: 10.1080/0284186X.2017.1374559

80. Trip AK, Jensen MB, Kallehauge JF, Lukacova S. Individualizing the Radiotherapy Target Volume for Glioblastoma Using DTI-MRI: A Phase 0 Study on Coverage of Recurrences. Acta Oncol (2019) 58(10):1-4. doi: 10.1080/0284186X.2019.1637018

81. Price SJ, Jena R, Burnet NG, Carpenter TA, Pickard JD, Gillard JH. Predicting Patterns of Glioma Recurrence Using Diffusion Tensor Imaging. Eur Radiol (2007) 17(7):1675-84. doi: 10.1007/s00330-006-0561-2

82. Wilmes LJ, Li W, Shin HJ, Newitt DC, Proctor E, Harnish R, Hylton NM. Diffusion Tensor Imaging for Assessment of Response to Neoadjuvant Chemotherapy in Patients With Breast Cancer. Tomography (2016) 2 (4):438-47. doi: 10.18383/j.tom.2016.00271

83. Furman-Haran E, Nissan N, Ricart-Selma V, Martinez-Rubio C, Degani H, Camps-Herrero J. Quantitative Evaluation of Breast Cancer Response to Neoadjuvant Chemotherapy by Diffusion Tensor Imaging: Initial Results. $J$ Magn Reson Imaging (2018) 47(4):1080-90. doi: 10.1002/jmri.25855

84. Gerhardt J, Sollmann N, Hiepe P, Kirschke JS, Meyer B, Krieg SM, et al. Retrospective Ddistortion Correction of Diffusion Tensor Imaging Data by SemiElastic Image Fusion - Evaluation by Means of Anatomical Landmarks. Clin Neurol Neurosurg (2019) 183:105387. doi: 10.1016/..clineuro.2019.105387

85. Rodan LH, Poublanc J, Fisher JA, Sobczyk O, Mikulis DJ, Tein I. L-Arginine Effects on Cerebrovascular Reactivity, Perfusion and Neurovascular Coupling in MELAS (Mitochondrial Encephalomyopathy With Lactic Acidosis and Stroke-Like Episodes) Syndrome. PloS One (2020) 15(9): e0238224. doi: 10.1371/journal.pone.0238224

86. Mazzetto-Betti KC, Leoni RF, Pontes-Neto OM, Sturzbecher MJ, Santos AC, Leite JP, et al. Quantification of BOLD fMRI Parameters to Infer Cerebrovascular Reactivity of the Middle Cerebral Artery. J Magn Reson Imaging (2013) 38(5):1203-9. doi: 10.1002/jmri.23943

87. Roux FE, Boulanouar K, Ranjeva JP, Tremoulet M, Henry P, Manelfe C, et al. Usefulness of Motor Functional MRI Correlated to Cortical Mapping in
Rolandic Low-Grade Astrocytomas. Acta Neurochir (Wien) (1999) 141 (1):71-9. doi: 10.1007/s007010050268

88. Hirsch J, Ruge MI, Kim KH, Correa DD, Victor JD, Relkin NR, et al. An Integrated Functional Magnetic Resonance Imaging Procedure for Preoperative Mapping of Cortical Areas Associated With Tactile, Motor, Language, and Visual Functions. Neurosurgery (2000) 47(3):711-21. doi: 10.1097/00006123-200009000-00037

89. Roux FE, Ibarrola D, Tremoulet M, Lazorthes Y, Henry P, Sol JC, et al. Methodological and Technical Issues for Integrating Functional Magnetic Resonance Imaging Data in a Neuronavigational System. Neurosurgery (2001) 49(5):1145-56. doi: 10.1097/00006123-200111000-00025

90. Krings T, Schreckenberger M, Rohde V, Spetzger U, Sabri O, Reinges MH, et al. Functional MRI and 18F FDG-Positron Emission Tomography for Presurgical Planning: Comparison With Electrical Cortical Stimulation. Acta Neurochir (Wien) (2002) 144(9):889-99. doi: 10.1007/s00701-002-0992-8

91. Hertz-Pannier L, Gaillard WD, Mott SH, Cuenod CA, Bookheimer SY, Weinstein $S$, et al. Noninvasive Assessment of Language Dominance in Children and Adolescents With Functional MRI: A Preliminary Study. Neurology (1997) 48(4):1003-12. doi: 10.1212/wnl.48.4.1003

92. Brannen JH, Badie B, Moritz CH, Quigley M, Meyerand ME, Haughton VM. Reliability of Functional MR Imaging With Word-Generation Tasks for Mapping Broca's Area. AJNR Am J Neuroradiol (2001) 22(9):1711-8.

93. Benson RR, FitzGerald DB, LeSueur LL, Kennedy DN, Kwong KK, Buchbinder BR, et al. Language Dominance Determined by Whole Brain Functional MRI in Patients With Brain Lesions. Neurology (1999) 52 (4):798-809. doi: 10.1212/wnl.52.4.798

94. Liu M, Guo X, Wang S, Jin M, Wang Y, Li J, et al. BOLD-MRI of Breast Invasive Ductal Carcinoma: Correlation of $\mathrm{R}^{*}$ Value and the Expression of HIF-1 $\alpha$. Eur Radiol (2013) 23(12):3221-7. doi: 10.1007/ s00330-013-2937-4

95. Wang M, Ma H, Wang X, Guo Y, Xia X, Xia H, et al. Integration of BOLDfMRI and DTI Into Radiation Treatment Planning for High-Grade Gliomas Located Near the Primary Motor Cortexes and Corticospinal Tracts. Radiat Oncol (2015) 10:64. doi: 10.1186/s13014-015-0364-1

96. Pantelis E, Papadakis N, Verigos K, Stathochristopoulou I, Antypas C, Lekas L, et al. Integration of Functional MRI and White Matter Tractography in Stereotactic Radiosurgery Clinical Practice. Int J Radiat Oncol Biol Phys (2010) 78(1):257-67. doi: 10.1016/j.ijrobp.2009.10.064

97. Petrella JR, Shah LM, Harris KM, Friedman AH, George TM, Sampson JH, et al. Preoperative Functional MR Imaging Localization of Language and Motor Areas: Effect on Therapeutic Decision Making in Patients With Potentially Resectable Brain Tumors. Radiology (2006) 240(3):793-802. doi: 10.1148/radiol.2403051153

98. Michelich CR, Song AW, Macfall JR. Dependence of Gradient-Echo and Spin-Echo BOLD fMRI at $4 \mathrm{~T}$ on Diffusion Weighting. NMR BioMed (2006) 19(5):566-72. doi: 10.1002/nbm.1035

99. Song AW, Li T. Improved Spatial Localization Based on Flow-MomentNulled and Intra-Voxel Incoherent Motion-Weighted fMRI. NMR BioMed (2003) 16(3):137-43. doi: 10.1002/nbm.819

100. Agarwal S, Sair HI, Gujar S, Hua J, Lu H, Pillai JJ. Functional Magnetic Resonance Imaging Activation Optimization in the Setting of Brain TumorInduced Neurovascular Uncoupling Using Resting-State Blood Oxygen Level-Dependent Amplitude of Low Frequency Fluctuations. Brain Connect (2019) 9(3):241-50. doi: 10.1089/brain.2017.0562

101. Voss HU, Peck KK, Petrovich Brennan NM, Pogosbekyan EL, Zakharova NE, Batalov AI, et al. A Vascular-Task Response Dependency and its Application in Functional Imaging of Brain Tumors. J Neurosci Methods (2019) 322:10-22. doi: 10.1016/j.jneumeth.2019.04.004

102. Yeom KW, Lober RM, Mobley BC, Harsh G, Vogel H, Allagio R, et al. Diffusion-Weighted MRI: Distinction of Skull Base Chordoma From Chondrosarcoma. AJNR Am J Neuroradiol (2013) 34(5):1056-61. doi: 10.3174/ajnr.A3333

103. Taouli B, Beer AJ, Chenevert T, Collins D, Lehman C, Matos C, et al. Diffusion-Weighted Imaging Outside the Brain: Consensus Statement From an ISMRM-Sponsored Workshop. J Magn Reson Imaging (2016) 44(3):52140. doi: $10.1002 / j m r i .25196$ 
104. Rana S, Albayram S, Lin DDM, Yousem David M. Diffusion-Weighted Imaging and Apparent Diffusion Coefficient Maps in a Case of Intracerebral Abscess With Ventricular Extension. AJNR Am J Neuroradiol (2002) 23 (1):109-12.

105. El KRM, Choudhary AK, Tappouni R. Accuracy of Apparent Diffusion Coefficient Value Measurement on PACS Workstation: A Comparative Analysis. AJR Am J Roentgenol (2011) 196(3):W280-4. doi: 10.2214/ AJR.10.4706

106. Mascalchi M, Filippi M, Floris R, Fonda C, Gasparotti R, Villari N. DiffusionWeighted MR of the Brain: Methodology and Clinical Application. Radiol Med (2005) 109(3):155-97.

107. Gurney-Champion OJ, Mahmood F, van SM, Julian R, George B, Philippens MEP, et al. Quantitative Imaging for Radiotherapy Purposes. Radiother Oncol (2020) 146:66-75. doi: 10.1016/j.radonc.2020.01.026

108. Allarakha A, Gao Y, Wang PJ. Progresses of MRI Diagnosis in Breast Cancer. Chin J Med Imaging Technol (2018) 34(2):306-9. doi: 10.4103/ 2347-5625.158017

109. Chandarana H, Wang H, Tijssen RHN, Das IJ. Emerging Role of MRI in Radiation Therapy. J Magn Reson Imaging (2018) 48(6):1468-78. doi: $10.1002 /$ jmri.26271

110. Xie M, Ren Z, Bian D, Li D, Yu L, Zhu F, et al. High Resolution DiffusionWeighted Imaging With Readout Segmentation of Long Variable EchoTrains for Determining Myometrial Invasion in Endometrial Carcinoma. Cancer Imaging (2020) 20(1):66. doi: 10.1186/s40644-020-00346-7

111. Esthappan J, Ma DJ, Narra VR, Raptis CA, Grigsby PW. Comparison of Apparent Diffusion Coefficient Maps to T2-Weighted Images for Target Delineation in Cervix Cancer Brachytherapy. J Contemp Brachyther (2011) 3 (4):193-8. doi: 10.5114/jcb.2011.26470

112. Marchiq I, Pouysségur J. Hypoxia, Cancer Metabolism and the Therapeutic Benefit of Targeting Lactate/H(+) Symporters. J Mol Med (Berl) (2016) 94 (2):155-71. doi: 10.1007/s00109-015-1307-x

113. Suppiah S, Rahmat K, Mohd-Shah MN, Azlan CA, Tan LK, Aziz YFA, et al. Improved Diagnostic Accuracy in Differentiating Malignant and Benign Lesions Using Single-Voxel Proton MRS of the Breast at 3 T MRI. Clin Radiol (2013) 68(9):e502-10. doi: 10.1016/j.crad.2013.04.002

114. Zeng QS, Li CF, Liu H, Zhen JH, Feng DC. Distinction Between Recurrent Glioma and Radiation Injury Using Magnetic Resonance Spectroscopy in Combination With Diffusion-Weighted Imaging. Int J Radiat Oncol Biol Phys (2007) 68(1):151-8. doi: 10.1016/j.ijrobp.2006.12.001

115. Li X, Zhu Y, Kang H, Zhang Y, Liang H, Wang S, et al. Glioma Grading by Microvascular Permeability Parameters Derived From Dynamic ContrastEnhanced MRI and Intratumoral Susceptibility Signal on Susceptibility Weighted Imaging. Cancer Imaging (2015) 15(1):4. doi: 10.1186/s40644015-0039-z

116. Torheim T, Groendahl AR, Andersen EK, Lyng H, Malinen E, Kvaal K, et al. Cluster Analysis of Dynamic Contrast Enhanced MRI Reveals Tumor Subregions Related to Locoregional Relapse for Cervical Cancer Patients. Acta Oncol (2016) 55(11):1294-8. doi: 10.1080/0284186X. 2016.1189091

117. van DFA, van DGM, Engelbrecht MR, van LGJ, Verhofstad A, Rijpkema M, et al. Combined Quantitative Dynamic Contrast-Enhanced MR Imaging and (1)H MR Spectroscopic Imaging of Human Prostate Cancer. J Magn Reson Imaging (2004) 20(2):279-87. doi: 10.1002/jmri.20113

118. Lund KV, Simonsen TG, Kristensen GB, Rofstad EK. Pharmacokinetic Analysis of DCE-MRI Data of Locally Advanced Cervical Carcinoma With the Brix Model. Acta Oncol (2019) 58(6):828-37. doi: 10.1080/ 0284186X.2019.1580386

119. Lund KV, Simonsen TG, Kristensen GB, Rofstad EK. DCE-MRI of LocallyAdvanced Carcinoma of the Uterine Cervix: Tofts Analysis Versus nonModel-Based Analyses. Radiat Oncol (2020) 15(1):79. doi: 10.1186/s13014020-01526-2

120. Filoti DI, Shire SJ, Yadav S, Laue TM. Comparative Study of Analytical Techniques for Determining Protein Charge. J Pharm Sci (2015) 104 (7):2123-31. doi: 10.1002/jps.24454

121. Hardee ME, Zagzag D. Mechanisms of Glioma-Associated Neovascularization. Am J Pathol (2012) 181(4):1126-41. doi: 10.1016/j.ajpath.2012.06.030

122. Li KL, Zhu XP, Checkley DR, Tessier JJ, Hillier VF, Waterton JC, et al. Simultaneous Mapping of Blood Volume and Endothelial Permeability
Surface Area Product in Gliomas Using Iterative Analysis of First-Pass Dynamic Contrast Enhanced MRI Data. Br J Radiol (2003) 76(901):39-50. doi: $10.1259 / \mathrm{bjr} / 31662734$

123. Medina LS, Bernal B, Dunoyer C, Cervantes L, Rodriguez M, Pacheco E, et al. Seizure Disorders: Functional MR Imaging for Diagnostic Evaluation and Surgical Treatment-Prospective Study. Radiology (2005) 236(1):247-53. doi: 10.1148/radiol.2361040690

124. Sun L, Qu B, Wang J, Ju Z, Zhang Z, Cui Z, et al. Integration of Functional MRI and White Matter Tractography in CyberKnife Radiosurgery. Technol Cancer Res Treat (2017) 16(6):850-6. doi: 10.1177/1533034617705283

125. Schad LR, Blüml S, Zuna IIX. MR Tissue Characterization of Intracranial Tumors by Means of Texture Analysis. Magn Reson Imaging (1993) 11 (6):889-96. doi: 10.1016/0730-725x(93)90206-s

126. van der Heide UA, Houweling AC, Groenendaal G, Beets-Tan RG, Lambin P. Functional MRI for Radiotherapy Dose Painting. Magn Reson Imaging (2012) 30(9):1216-23. doi: 10.1016/j.mri.2012.04.010

127. Prasetyanti PR, Medema JP. Intra-Tumor Heterogeneity From a Cancer Stem Cell Perspective. Mol Cancer (2017) 16(1):41. doi: 10.1186/s12943-017-0600-4

128. Onjukka E, Uzan J, Baker C, Howard L, Nahum A, Syndikus I. Twenty Fraction Prostate Radiotherapy With Intra-Prostatic Boost: Results of a Pilot Study. Clin Oncol (R Coll Radiol) (2017) 29(1):6-14. doi: 10.1016/ j.clon.2016.09.009

129. Pollack A, Chinea FM, Bossart E, Kwon D, Abramowitz MC, Lynne C, et al. Phase I Trial of MRI-Guided Prostate Cancer Lattice Extreme Ablative Dose (LEAD) Boost Radiation Therapy. Int J Radiat Oncol Biol Phys (2020) 107 (2):305-15. doi: 10.1016/j.ijrobp.2020.01.052

130. Uzan J, Nahum AE, Syndikus. Prostate Dose-painting Radiotherapy I. And Radiobiological Guided Optimisation Enhances the Therapeutic Ratio. Clin Oncol (R Coll Radiol) (2016) 28(3):165-70. doi: 10.1016/j.clon.2015.09.006

131. von Eyben FE, Kiljunen T, Kangasmaki A, Kairemo K, von Eyben R, Joensuu T. Radiotherapy Boost for the Dominant Intraprostatic Cancer Lesion-A Systematic Review and Meta-Analysis. Clin Genitourin Cancer (2016) 14 (3):189-97. doi: 10.1016/j.clgc.2015.12.005

132. Henke L, Kashani R, Robinson C, Curcuru A, DeWees T, Bradley J, et al. Phase I Trial of Stereotactic MR-Guided Online Adaptive Radiation Therapy (SMART) for the Treatment of Oligometastatic or Unresectable Primary Malignancies of the Abdomen. Radiother Oncol (2018) 126(3):519-26. doi: 10.1016/j.radonc.2017.11.032

133. Ling CC, Humm J, Larson S, Amols H, Fuks Z, Leibel S, et al. Towards Multidimensional Radiotherapy (MD-CRT): Biological Imaging and Biological Conformality. Int J Radiat Oncol Biol Phys (2000) 47(3):551-60. doi: 10.1016/s0360-3016(00)00467-3

134. van Der Wel A, Nijsten S, Hochstenbag M, Lamers R, Boersma L, Wanders $\mathrm{R}$, et al. Increased Therapeutic Ratio by 18FDG-PET CT Planning in Patients With Clinical CT Stage N2-N3M0 non-Small-Cell Lung Cancer: A Modeling Study. Int J Radiat Oncol Biol Phys (2005) 61(3):649-55. doi: 10.1016/ j.ijrobp.2004.06.205

135. Forastiere AA, Zhang Q, Weber RS, Maor MH, Goepfert H, Pajak TF, et al. Long-Term Results of RTOG 91-11: A Comparison of Three Nonsurgical Treatment Strategies to Preserve the Larynx in Patients With Locally Advanced Larynx Cancer. J Clin Oncol (2013) 31(7):845-52. doi: 10.1200/ JCO.2012.43.6097

136. Nutting CM, Morden JP, Harrington KJ, Urbano TG, Bhide SA, Clark C, et al. Parotid-Sparing Intensity Modulated Versus Conventional Radiotherapy in Head and Neck Cancer (PARSPORT): A Phase 3 Multicentre Randomised Controlled Trial. Lancet Oncol (2011) 12(2):12736. doi: 10.1016/S1470-2045(10)70290-4

137. Wang J, Zheng J, Tang T, Zhu F, Yao Y, Xu J, et al. A Randomized Pilot Trial Comparing Position Emission Tomography (PET)-Guided Dose Escalation Radiotherapy to Conventional Radiotherapy in Chemoradiotherapy Treatment of Locally Advanced Nasopharyngeal Carcinoma. PLoS One (2015) 10(4):e0124018. doi: 10.1371/journal.pone.0124018

138. Houweling AC, Wolf AL, Vogel WV, Hamming-Vrieze O, van VlietVroegindeweij C, van de Kamer JB, et al. FDG-PET and Diffusion-Weighted MRI in Head-and-Neck Cancer Patients: Implications for Dose Painting. Radiother Oncol (2013) 106(2):250-4. doi: 10.1016/j.radonc.2013.01.003

139. Grönlund E, Johansson S, Nyholm T, Thellenberg C, Ahnesjö A. Dose Painting of Prostate Cancer Based on Gleason Score Correlations With 
Apparent Diffusion Coefficients. Acta Oncol (2018) 57(5):574-81. doi: 10.1080/0284186X.2017.1415457

140. Abedi I, Tavakkoli MB, Jabbari K, Amouheidari A, Yadegarfard. Dosimetric G. And Radiobiological Evaluation of Multiparametric MRI-Guided Dose Painting in Radiotherapy of Prostate Cancer. J Med Signals Sens (2017) 7 (2):114-21.

141. Laprie A, Ken S, Filleron T, Lubrano V, Vieillevigne L, Tensaouti F, et al. Dose-Painting Multicenter Phase III Trial in Newly Diagnosed Glioblastoma: The SPECTRO-GLIO Trial Comparing Arm A Standard Radiochemotherapy to Arm B Radiochemotherapy With Simultaneous Integrated Boost Guided by MR Spectroscopic Imaging. BMC Cancer (2019) 19(1):167. doi: 10.1186/s12885-019-5317-x

142. Hunt A, Hansen VN, Oelfke U, Nill S, Hafeez S. Adaptive Radiotherapy Enabled by MRI Guidance. Clin Oncol (R Coll Radiol) (2018) 30(11):711-9. doi: 10.1016/j.clon.2018.08.001

143. Kupelian P, Sonke JJ. Magnetic Resonance-Guided Adaptive Radiotherapy: A Solution to the Future. Semin Radiat Oncol (2014) 24(3):227-32. doi: 10.1016/j.semradonc.2014.02.013

144. Grønborg C, Vestergaard A, Høyer M, Söhn M, Pedersen EM, Petersen. Intra-fractional bladder motion JB. And Margins in Adaptive Radiotherapy for Urinary Bladder Cancer. Acta Oncol (2015) 54(9):1461-6. doi: 10.3109/ 0284186X.2015.1062138

145. Vestergaard A, Hafeez S, Muren LP, Nill S, Høyer M, Hansen VN, et al. The Potential of MRI-Guided Online Adaptive Re-Optimisation in Radiotherapy of Urinary Bladder Cancer. Radiother Oncol (2016) 118(1):154-9. doi: 10.1016/j.radonc.2015.11.003

146. Pötter R, Tanderup K, Schmid MP, Jürgenliemk-Schulz I, Haie-Meder C, Fokdal LU, et al. MRI-Guided Adaptive Brachytherapy in Locally Advanced Cervical Cancer (EMBRACE-I): A Multicentre Prospective Cohort Study. Lancet Oncol (2021) 22(4):538-47. doi: 10.1016/S1470-2045 (20)30753-1

147. Tan Mbbs Mrcp Frcr LT, Tanderup DK, Kirisits DC, de Leeuw DA, Nout Md DR, Duke Mbbs Frcr S, et al. Image-Guided Adaptive Radiotherapy in Cervical Cancer. Semin Radiat Oncol (2019) 29(3):284-98. doi: 10.1016/ j.semradonc.2019.02.010

148. Westerveld H, Nesvacil N, Fokdal L, Chargari C, Schmid MP, Milosevic M, et al. Definitive Radiotherapy With Image-Guided Adaptive Brachytherapy for Primary Vaginal Cancer. Lancet Oncol (2020) 21(3):e157-67. doi: 10.1016/S1470-2045(19)30855-1

149. Witt JS, Rosenberg SA, Bassetti MF. MRI-Guided Adaptive Radiotherapy for Liver Tumours: Visualising the Future. Lancet Oncol (2020) 21(2):e74-82. doi: 10.1016/S1470-2045(20)30034-6

150. Bruynzeel AME, Tetar SU, Oei SS, Senan S, Haasbeek CJA, Spoelstra FOB, et al. A Prospective Single-Arm Phase 2 Study of Stereotactic Magnetic Resonance Guided Adaptive Radiation Therapy for Prostate Cancer: Early Toxicity Results. Int J Radiat Oncol Biol Phys (2019) 105(5):1086-94. doi: 10.1016/j.ijrobp.2019.08.007

151. Parvez K, Parvez A, Zadeh. The diagnosis G. And Treatment of Pseudoprogression, Radiation Necrosis and Brain Tumor Recurrence. Int $J$ Mol Sci (2014) 15(7):11832-46. doi: 10.3390/ijms150711832

152. Xu JL, Li YL, Lian JM, Dou SW, Yan FS, Wu H, et al. Distinction Between Postoperative Recurrent Glioma and Radiation Injury Using MR Diffusion Tensor Imaging. Neuroradiology (2010) 52(12):1193-9. doi: 10.1007/s00234010-0731-4

153. Larsen VA, Simonsen HJ, Law I, Larsson HB, Hansen AE. Evaluation of Dynamic Contrast-Enhanced T1-Weighted Perfusion MRI in the Differentiation of Tumor Recurrence From Radiation Necrosis. Neuroradiology (2013) 55(3):361-9. doi: 10.1007/s00234-012-1127-4

154. Verma N, Cowperthwaite MC, Burnett MG, Markey MK. Differentiating Tumor Recurrence from Treatment Necrosis: A Review of Neuro-Oncologic Imaging Strategies. Neuro Oncol (2013) 15(5):515-34. doi: 10.1093/neuonc/ $\operatorname{nos} 307$

155. Groot Koerkamp ML, Vasmel JE, Russell NS, Shaitelman SF, Anandadas CN, Currey A, et al. Optimizing MR-Guided Radiotherapy for Breast Cancer Patients. Front Oncol (2020) 10:1107. doi: 10.3389/fonc.2020.01107

156. Podder TK, Fredman ET, Ellis RJ. Advances in Radiotherapy for Prostate Cancer Treatment. Adv Exp Med Biol (2018) 1096:31-47. doi: 10.1007/9783-319-99286-0_2
157. Cusumano D, Boldrini L, Menna S, Teodoli S, Placidi E, Chiloiro G, et al. Evaluation of a Simplified Optimizer for MR-Guided Adaptive RT in Case of Pancreatic Cancer. J Appl Clin Med Phys (2019) 20(9):20-30. doi: 10.1002/ acm2.12697

158. Hall W, Straza M, Chen X, Mickevicius N, Erickson B, Schultz C, et al. Initial Clinical Experience of Stereotactic Body Radiation Therapy (SBRT) for Liver Metastases, Primary Liver Malignancy, and Pancreatic Cancer With 4D-MRI Based Online Adaptation and Real-Time MRI Monitoring Using a 1.5 Tesla MR-Linac. PLoS One (2020) 15(8):e0236570. doi: 10.1371 /journal

159. Tocco BR, Kishan AU, Ma TM, Kerkmeijer LGW, Tree. MR-Guided Radiotherapy for Prostate Cancer. Front Oncol AC. (2020) 10:616291. doi: $10.3389 /$ fonc.2020.616291

160. Raaymakers BW, Raaijmakers AJ, Lagendijk JJ. Feasibility of MRI Guided Proton Therapy: Magnetic Field Dose Effects. Phys Med Biol (2008) 53 (20):5615-22. doi: 10.1088/0031-9155/53/20/003

161. Mowatt G, Scotland G, Boachie C, Cruickshank M, Ford JA, Fraser C, et al. The Diagnostic Accuracy and Cost-Effectiveness of Magnetic Resonance Spectroscopy and Enhanced Magnetic Resonance Imaging Techniques in Aiding the Localisation of Prostate Abnormalities for Biopsy: A Systematic Review and Economic Evaluation. Health Technol Assess (2013) 17(20):viixix, 1-281. doi: 10.3310/hta17200

162. Cerantola Y, Dragomir A, Tanguay S, Bladou F, Aprikian A, Kassouf W. Cost-Effectiveness of Multiparametric Magnetic Resonance Imaging and Targeted Biopsy in Diagnosing Prostate Cancer. Urol Oncol (2016) 34 (3):119.e1-9. doi: 10.1016/j.urolonc.2015.09.010

163. Gordon LG, James R, Tuffaha HW, Lowe A, Yaxley J. Cost-Effectiveness Analysis of Multiparametric MRI With Increased Active Surveillance for Low-Risk Prostate Cancer in Australia. J Magn Reson Imaging (2017) 45 (5):1304-15. doi: 10.1002/jmri.25504

164. Barnett CL, Davenport MS, Montgomery JS, Kunju LP, Denton BT, Piert M. (18)F-Choline PET/mpMRI for Detection of Clinically Significant Prostate Cancer: Part 2. Cost-Effectiveness Analysis. J Nucl Med (2019) 60(12):170512. doi: $10.2967 /$ jnumed.119.225771

165. Macleod LC, Yabes JG, Fam MM, Bandari J, Yu M, Maganty A, et al. Multiparametric Magnetic Resonance Imaging Is Associated With Increased Medicare Spending in Prostate Cancer Active Surveillance. Eur Urol Focus (2020) 6(2):242-8. doi: 10.1016/j.euf.2019.04.008

166. Walton Diaz A, Shakir NA, George AK, Rais-Bahrami S, Turkbey B, Rothwax JT, et al. Use of Serial Multiparametric Magnetic Resonance Imaging in the Management of Patients With Prostate Cancer on Active Surveillance. Urol Oncol (2015) 33(5):202.e1-7. doi: 10.1016/j.urolonc. 2015.01.023

167. Nassiri N, Margolis DJ, Natarajan S, Sharma DS, Huang J, Dorey FJ, et al. Targeted Biopsy to Detect Gleason Score Upgrading During Active Surveillance for Men With Low Versus Intermediate Risk Prostate Cancer. J Urol (2017) 197(3 Pt 1):632-9. doi: 10.1016/j.juro.2016.09.070

168. Lotan Y, Haddad AQ, Costa DN, Pedrosa I, Rofsky NM, Roehrborn CG. Decision Analysis Model Comparing Cost of Multiparametric Magnetic Resonance Imaging vs. Repeat Biopsy for Detection of Prostate Cancer in Men With Prior Negative Findings on Biopsy. Urol Oncol (2015) 33 (6):266.e9-16. doi: 10.1016/j.urolonc.2015.03.007

169. Faria R, Soares MO, Spackman E, Ahmed HU, Brown LC, Kaplan R, et al. Optimising the Diagnosis of Prostate Cancer in the Era of Multiparametric Magnetic Resonance Imaging: A Cost-Effectiveness Analysis Based on the Prostate MR Imaging Study (PROMIS). Eur Urol (2018) 73(1):23-30. doi: 10.1016/j.eururo.2017.08.018

170. Patel S, Rongen JJ, Fütterer JJ, Boltyenkov A, Rovers MM. The Role of Multiparametric Magnetic Resonance Imaging in Active Surveillance for Men With Low-Risk Prostate Cancer: A Cost-Effectiveness Modeling Study. Eur Urol Oncol (2018) 1(6):476-83. doi: 10.1016/j.euo. 2018.05.007

171. Lee N, Schoder H, Beattie B, Lanning R, Riaz N, McBride S, et al. Strategy of Using Intratreatment Hypoxia Imaging to Selectively and Safely Guide Radiation Dose De-Escalation Concurrent With Chemotherapy for Locoregionally Advanced Human Papillomavirus-Related Oropharyngeal Carcinoma. Int J Radiat Oncol Biol Phys (2016) 96(1):9-17. doi: 10.1016/ j.ijrobp.2016.04.027 
172. Riaz N, Sherman E, Pei X, Schöder H, Grkovski M, Paudyal R, et al. Precision Radiotherapy: Reduction in Radiation for Oropharyngeal Cancer in the 30 ROC Trial. J Natl Cancer Inst (2021) 113(6):742-51. doi: 10.1093/jnci/ djaal 184

Conflict of Interest: The authors declare that the research was conducted in the absence of any commercial or financial relationships that could be construed as a potential conflict of interest.

Publisher's Note: All claims expressed in this article are solely those of the authors and do not necessarily represent those of their affiliated organizations, or those of the publisher, the editors and the reviewers. Any product that may be evaluated in this article, or claim that may be made by its manufacturer, is not guaranteed or endorsed by the publisher.

Copyright $\odot 2021 \mathrm{Li}$, Zhang and Yang. This is an open-access article distributed under the terms of the Creative Commons Attribution License (CC BY). The use, distribution or reproduction in other forums is permitted, provided the original author $(s)$ and the copyright owner(s) are credited and that the original publication in this journal is cited, in accordance with accepted academic practice. No use, distribution or reproduction is permitted which does not comply with these terms. 